Revista Eletrônica do Mestrado em Educação Ambiental

\title{
Análise das práticas de Educação Ambiental das cervejarias do Rio Grande do Sul
}

\author{
Samuel Vinícius Bonato ${ }^{1}$ \\ FURG \\ ORCID 0000-0002-2486-4909
}

Resumo: Este artigo analisou as práticas de educação ambiental atualmente realizadas pelas cervejarias do Rio Grande do Sul, buscando contribuir para a disseminação do conceito de EA dentro do setor privado, visto que este muitas vezes pratica ações voltadas para este viés, mas ainda permanece em estágio inicial na interpretação do conceito. O estudo foi realizado em 18 cervejarias do estado do RS, as quais foram entrevistadas para identificação de práticas implementadas internamente e também práticas relacionadas às ações de EA nas interações com suas comunidades locais. Como principais resultados, destaca-se a identificação de 7 práticas de EA já em andamento dentro das empresas e também o envolvimento dos gestores na aplicação destas não só para obter retornos financeiros, mas sim também para retornos relacionados às questões ambientais.

Palavras-chave: Educação Ambiental; Gestão Ambiental; Cervejaria

\section{Análisis de las prácticas de Educación Ambiental de la cervejarias del Rio Grande do}

\section{Sul}

Resumen: Este articulo analizó las prácticas de educación ambiental actualmente realizadas por las cervejarias del Rio Grande do Sul, con la intención de contribuir a la diseminación del concepto de EA dentro del sector privado, ya que este muchas veces practica acciones dirigidas para este viés, pero aún permanece en práctica inicial en la interpretación del concepto. El estudio fue realizado en 18 cervejarias del estado do Rio Grande do Sul, que fueron entrevistadas para identificación de practicas implementadas internamente y también prácticas relacionadas a las acciones de EA en las interacciones con sus comunidades locales. Como principales resultados, se destaca la indentificación de 7 prácticas de EA ya en marcha dentro de las empresas y también la participación de los gestores en la aplicación de estas no sólo para obtener retornos financieros, pero sí también para retornos relacionados a las cuestiones ambientales.

Palabras-clave: Educación Ambiental; Gestión Ambiental; Cervejaria

\footnotetext{
${ }^{1}$ Doutor em Engenharia de Produção pela Universidade Federal do Rio Grande do Sul (2016), Possui graduação em Administração de Empresas pela Universidade Federal do Rio Grande (2004) e MBA em Gerenciamento de Projetos pela Fundação Getúlio Vargas (2008). Experiência de 15 anos em implantação de Sistemas de Gestão, atualmente é Professor Adjunto na FURG, atuando nas áreas de Logística, Gestão de Projetos e Gestão Ambiental. e-mail: $\underline{\text { svbonato@ gmail.com }}$
} 


\title{
Environmental Education practices analysis on South Brazil breweries
}

\begin{abstract}
This article analyzes the environmental education practices currently carried out by the breweries of Rio Grande do Sul, seeking to contribute to the dissemination of the EE concept within the private sector, since it often practices actions related to this concept, but remains in a begginer stage of the concept's interpretation. The study was conducted in 18 breweries in the state of RS, as were interviewed for the identification of internally implemented practices and also practices related to the actions of $\mathrm{EE}$ in the interactions with their local communities. The main results highlight the identification of 7 EA practices already in progress within companies and also the involvement of managers in its application not only to obtain financial returns, but also for returns related to environmental issues.

Key-words: Environmental Education; Environmental Management, Brewery
\end{abstract}

\section{Introdução}

A busca por iniciativas ambientais dentro das organizações tem sido um desafio cada vez mais intenso para os gestores que lideram equipes dos mais diversos segmentos (RAMUS, 2002). Para o alcance destas iniciativas, entretanto, o despertar de uma consciência mais ecológica e o alinhamento de práticas internas envolvendo todos os seus atores deveriam ser encorajados diariamente, visto que a educação das pessoas para a questão ambiental a cada dia é alterada significativa por diversas forças globais (JICKLING; WALS, 2008).

A proposta pedagógica da educação ambiental se sustenta na conscientização, mudança de comportamento, desenvolvimento de competências, capacidade de avaliação e participação das pessoas. Cada vez mais a relação entre meio ambiente e educação assume um papel fundamental para a absorção de novos saberes, principalmente no que se refere à aprendizagem de processos sociais complexos e riscos ambientais que se intensificam (JACOBI, 2004).

Se por um lado, a cada ano as organizações têm se tornado mais conscientes em relação às necessidades de redução dos impactos ambientais de suas operações (HOFER; CANTOR; DAI, 2012; MEZINSKA; STRODE, 2015), por outro lado, as pressões sociais e ambientais para esta redução também crescem a cada instante, levando empresas tanto de países desenvolvidos como de países subdesenvolvidos a modificar seus processos industriais e trabalhar de forma mais intensa na preparação das pessoas para uma educação ambiental mais consistente (MUSSATO; DRAGONE; ROBERTO, 2006).

Em paralelo a este novo momento em relação a abordagens de gestão e educação ambiental, a possibilidade de fabricação de cerveja é uma questão que tem atraído, nos últimos anos, muitos adeptos dentro do estado do Rio Grande do Sul (RS). O processo de 
fabricação, por não ser um processo complicado, pode ser feito em grandes, médias, pequenas e micro cervejarias e, inclusive, pode ser realizado artesanalmente, em casa. $\mathrm{O}$ crescimento deste setor no RS fica evidente quando o BRASIL-MAPA (2016) informa que, no final de 2015 existiam 89 cervejarias gaúchas registradas no Ministério da Agricultura, Pecuária e Abastecimento (MAPA), contra 59 encontradas nos registros deste Ministério ao final de 2014, ou seja, um incremento de mais de $50 \%$ no número de cervejarias.

Este crescimento substancial do número de cervejarias pode ser considerado como um avanço benéfico e que contribui em muito para o crescimento econômico do setor e do estado do Rio Grande do Sul, porém é inegável que somente as questões econômicas não são mais os únicos objetivos que uma organização deve focar em alcançar a partir de sua atuação. Neste caso, ainda há toda a questão social e principalmente a questão ambiental, pilares formadores, junto com a questão econômica, do tripé da sustentabilidade.

Apesar das cervejarias serem consideradas como operações limpas quanto à sua atividade e não pró-ativas em relação à importância dada a questões ambientais (LUCAS; NOORDEWIER, 2016), as maiores preocupações em relação a este segmento estão relacionadas a poluição da água e ao descarte de resíduos (OLAJIRE, 2012). Nesse sentido, desenvolver uma maior pró-atividade das pessoas, através de práticas voltadas para educação ambiental, pode trazer benefícios em forma de melhorias tanto no desempenho ambiental como em relação à custos (GRAHAN; POTTER, 2015).

Este artigo tem como objetivo analisar as práticas de educação ambiental atualmente realizadas pelas cervejarias do Rio Grande do Sul, buscando-se identificar possíveis iniciativas já práticas dentro deste segmento e que possam contribuir para a disseminação do conceito de educação ambiental neste ramo de atividade.

Para atingir este objetivo, a segunda seção do trabalho apresenta conceitos amplos relacionados à gestão e educação ambiental, bem como um aprofundamento em relação a estes temas e sua importância. A terceira seção apresenta os procedimentos metodológicos utilizados, a quarta seção os resultados da pesquisa realizada e por fim, a quinta seção salienta as conclusões e contribuições deste estudo para a área.

\section{Fundamentação}

\section{Educação Ambiental}

Rev. Eletrônica Mestr. Educ. Ambient. Rio Grande, v. 37, n. 3, p. 9-26, mai./ago. 2020. 
Para que se possa desenvolver uma abordagem adequada em relação à práticas de educação ambiental, torna-se necessário inicialmente o entendimento dos conceitos que permeiam este tema. Nesse sentido a lei 9.795/99 art. 1 define EA como:

\begin{abstract}
Entendem-se por educação ambiental os processos por meio dos quais o indivíduo e a coletividade constroem valores sociais, conhecimentos, habilidades, atitudes e competências voltadas para a conservação do meio ambiente, bem de uso comum do povo, essencial à sadia qualidade de vida e sua sustentabilidade (BRASIL, 1999).
\end{abstract}

A educação ambiental para uma sustentabilidade equitativa é um processo de aprendizagem permanente, afirmando afirma valores e ações que contribuem para a transformação humana e social e para a preservação ecológica (SANTANA, 2008), tendo um papel fundamental para a consciência das futuras gerações (DE ANDRADE ET AL., 2016).

Se conduzida de forma constante, a educação ambiental pode ser uma excelente ferramenta para facilitar a gestão ambiental, gerando valor para a organização. Entretanto, a educação ambiental corporativa caba se restringindo apenas a treinamentos, sendo que esta abordagem deveria ser muito mais ampla, incluindo a sensibilização dos colaboradores para a preservação ambiental (SILVA; MARTINS, 2015). Neste caso, a educação ambiental exercida nas empresas deveria ser conduzida da mesma forma como nas escolas, pois são exercidas sobre o mesmo sujeito e visam transformar as mesmas variáveis (KITZMANN; ASMUS, 2002). Mesmo assim, não é também apenas com a sensibilização que serão resolvidos os problemas ambientais, mas com ações, metas e objetivos mensuráveis que permitam que seja aferida a eficácia dos programas de educação ambiental (ANCIETA MELGAR; VAN BELLE, LUNKES, 2006).

Cada tem seu papel em relação às questões ambientais, porém a atuação ambiental destes depende principalmente de fatores organizacionais (RAMUS, 2002), que muitas vezes podem não conter as bases necessárias para uma educação ambiental consistente (FESZTEROVA; JOMOVA, 2015). Nesse sentido, a educação ambiental dos colaboradores não acontece apenas pelo repasse de informações, mas despertando o sentimento de responsabilidade compartilhada de cada um (VILELA JUNIOR; DEMAJOROVIC, 2006).

A Educação Ambiental é normalmente praticada fora dos limites das empresas, não sendo apenas uma abordagem que, com a reciclagem ou a sensibilização irá ser entendida e implementada. Além disso, é preciso ações e estabelecimento de objetivos e metas 
mensuráveis, que permitam aferir a eficácia da Educação Ambiental e seus programas (MELGAR, 2005). Para Rodriguez e Silva (2009), a Educação, e mais especificamente a Educação Ambiental contribui para a uma nova adaptação cultural que resultará em uma nova concepção e postura com o Meio Ambiente, sendo responsável por formar valores ambientais, diferentemente dos valores da modernidade.

\section{Gestão Ambiental}

Considera-se que para tornar possível o movimento da Gestão Ambiental, esta deve estar fundamentada pelo diálogo no qual se insere a Educação Ambiental. As se tratar o meio ambiente através de uma perspectiva formal de educação, atrela-se a gestão ambiental a esta abordagem (ASSIS; RUTKOWSKI, 2016).

Toda perspectiva presente atualmente dentro do processo cervejeiro, tem como base conceitos de gestão ambiental que cada vez mais emergem de uma origem teórica e migram para uma abordagem mais prática. Nesse sentido, além da fundamentação baseada na educação ambiental, torna-se relevante identificar de forma geral como a questão ambiental tem sido relacionada aos processos produtivos cervejeiros.

Sistematicamente as organizações têm evoluído na consciência de que devem reduzir os impactos ambientais de suas operações com o auxílio de ferramentas de gestão ambiental (HOFER; CANTOR; DAI, 2012; MEZINSKA; STRODE, 2015). Esta abordagem é um processo contínuo de adaptação constante, no qual uma organização define seus objetivos e metas de proteção ao meio ambiente e interação com o ambiente externo (ACRE; CASTILHO, 2013). Além disso, as pressões sociais e ambientais para a redução dos impactos ambientais das operações também crescem a cada instante, levando empresas a modificar e aprimorar seus processos para que sejam possíveis melhores resultados em termos de gestão de seus resíduos (MUSSATO; DRAGONE; ROBERTO, 2006).

A partir destas abordagens, cresce também a conscientização das empresas e das indústrias na responsabilidade em se adequarem a normas relativas à Gestão Ambiental. Esta responsabilidade está diretamente relacionada à influência que essas desejam provocar perante a sociedade, como uma forma de prevenção e cuidado com as gerações futuras, criando formas sustentáveis de produção (DONAIRE, 1999). Nesse sentido, a empresa que possui um Sistema de Gestão Ambiental (SGA) mostra sua preocupação com o meio 
ambiente a seus clientes e consumidores, quando faz valer a lei, agregando maior valor de mercado ao seu produto (BARBIERI, 2004).

Ainda em relação aos conceitos de gestão ambiental, surge também a proposta para uma Produção Mais Limpa $(\mathrm{P}+\mathrm{L})$, que trata sobre a redução de efeitos negativos, como os gastos gerados a partir do desperdício, tendo esta um caráter mais transitório, com o intuito de modificação dos processos para geração de menos resíduos (KUEHR, 2006). Desta forma, uma produção limpa (Cleaner Production - CP) deve focar na redução em quantidade e toxicidade de todas as emissões e resíduos antes dos mesmos deixarem o processo produtivo. As ferramentas existentes relacionadas a esta área separam a $\mathrm{CP}$ em dois grupos: $i$ ) orientados para redução de emissões e resíduos e, ii) orientados para a reutilização destas emissões e resíduos (RIVERA et al., 2009).

Segundo a UNEP (2016) a P+L é um viés de proteção ambiental que considera todo o ciclo de vida do produto e todo o processo produtivo, com o intuito de prevenir e eliminar os riscos da geração e consumo de resíduos para os seres humanos e o meio ambiente.

A Produção mais Limpa requer que as empresas reestruturem seus sistemas de produção de modo que elas possam utilizar seus recursos por completo. Com a Produção Mais Limpa, é feita uma análise (input - output) e há modificação do processo de produção e de processos unitários, visando atingir uma diminuição dos resíduos no estágio final da produção, reduzir o desperdício e o custo mínimo, sendo esta uma oportunidade de melhoria de negócios, de diminuição de custos, riscos e responsabilidades, na medida em que eleva a eficiência, a produtividade e a rentabilidade (VAN BERKEL, 2007).

Em contrapartida à Produção mais Limpa, o conceito de emissões zero requer o redesenho dos processos industriais para que os resíduos destes sejam totalmente reutilizados, sendo o "próximo passo" da evolução dos conceitos de produção limpa (cleaner production), conforme apresentados na Figura 1 (BRAUNGART; MCDONOUGH; BOLLINGER, 2006; KUEHR, 2007).

Figura 1: Diferenças entre Produção Limpa e Emissão Zero 


\begin{tabular}{|c|c|}
\hline $\begin{array}{c}\text { Produção Limpa } \\
\text { (Reduzir, Reciclar, Reutilizar) }\end{array}$ & $\begin{array}{c}\text { Emissão Zero } \\
\text { (Produtividade Total) }\end{array}$ \\
\hline Minimização dos efeitos posteriores & Novas indústrias na cadeia \\
\hline Minimização dos resíduos & Agregação de valor \\
\hline Mínimos custos & Aumento de receitas \\
\hline Modificação de processos individualmente & Agrupamento de empresas \\
\hline Análise de entradas e saidas & Conexão entre entradas e saidas \\
\hline $\begin{array}{c}\text { Minimização de resíduos através da } \\
\text { modificacão do processo de produção }\end{array}$ & Abordagem integral, geração de empregos \\
\hline Durante processo & Objetivo Final \\
\hline
\end{tabular}

Fonte: adaptado de Kuehr (2007)

Com um aprofundamento ainda maior da gestão ambiental, o conceito de Economia Circular (EC) tornou-se uma das propostas mais recentes na área de sustentabilidade ambiental (MURRAY ET AL., 2005). A Economia Circular é estabelecida através do seu direcionamento ao crescimento econômico, mas sempre considerando a redução de matéria-prima e energia em todos os estágios de produção e também visando a implementação de um novo e crescente conceito de empresas. Assim, existe a busca pela utilização dos produtos em sua totalidade e, dessa forma, a eliminação de desperdício (BILITEWSKI, 2012).

A EC propõe a abordagem de questões ambientais de forma a transformar desperdício em recursos, unindo a atividade de produção e consumo. A transição para um regime de EC requer uma mudança sistêmica e em níveis diversos, incluindo inovação tecnológica, novos modelos de negócios e colaboração de stakeholders (WITJES ET AL., 2016).

As instituições com responsabilidade sustentável, como mencionado anteriormente, adquirem retorno financeiro e visibilidade, no que diz respeito à garantia do bem-estar social, através da redução de geração de resíduos e consumo de materiais e energia. Essas teorias e práticas sustentáveis vêm sendo transformadas pela relevância da sustentabilidade (BACHA; SANTOS; SCHAUN, 2010), as quais conciliam retorno financeiro, social e ambiental das empresas, o chamado "tripé da sustentabilidade".

Segundo Tinoco e Pereira (2008), é possível obter retorno financeiro e proteger o meio ambiente com criatividade e condições internas que possam transformar restrições e ameaças ambientais em oportunidades de negócios. A empresa obtém boa imagem e agrega valor quando consegue ponderar gastos ambientais com políticas de investimento de curto e longo prazo obtendo competitividade (PAIVA, 2003). 
Com base nos conceitos apresentados, pode-se dizer que a gestão ambiental é um conceito amplo, subdividido em diversas abordagens que ao longo do tempo foram se tornando importantes para o desenvolvimento ambiental. Entretanto, apesar de diferentes vieses, pode-se afirmar que nenhuma abordagem torna-se suficiente sem haver uma forte sustentação educacional. Nesse sentido, a educação ambiental deve ser encarada como o pilar que trará o direcionamento prático dos indivíduos para que cada um dos conceitos apresentados seja operacionalizado de forma correta. No caso, das cervejarias, torna-se importante então, além de analisar como as empresas estão tornando as suas operações mais limpas, entender também que práticas de educação ambiental tem sido implementadas para tornar realidade a melhoria dos processos relacionados.

\section{Metodologia}

A primeira etapa deste trabalho foi a realização de uma pesquisa bibliográfica com base em artigos e livros buscando-se aprofundar uma análise teórica em relação aos conceitos de educação e gestão ambiental.

A segunda etapa foi a realização de uma pesquisa para levantamento de dados considerando as atuais práticas de educação ambiental atualmente praticadas pelas cervejarias do RS. Esta pesquisa foi caracterizada por ser: $i$ ) qualitativa, que para Gerhardt e Silveira (2009), visa a compreensão de dinâmicas e relações sociais, baseando-se em aspectos não quantificáveis; ii) de caráter exploratório, definido por Theodorson e Theodorson (1970) como um estudo preliminar com o intuito de familiarizar o pesquisador com o fenômeno investigado que suporte um estudo maior com melhor entendimento e precisão e; iii) realizada através de um roteiro semiestruturado e aplicada pelo autor através de entrevistas presenciais em cervejarias do estado do Rio Grande do Sul.

O universo da pesquisa foi composto pelas 98 cervejarias registradas pelo BRASILMAPA (2016), no momento da realização do estudo. A partir deste universo, foram desconsideradas as 3 cervejarias de grande porte e consideradas apenas 95 cervejarias com litragem mensal inferior a 10 milhões de litros (microcervejarias) e proposta uma estratificação da população em 4 regiões do estado do Rio Grande do Sul, a saber: Porto Alegre (POA), Grande Porto Alegre e Vale dos Sinos, Serra e Demais Regiões. A Figura 2 apresenta a divisão realizada por região, considerando o número de cervejarias por região. 
Figura 2: Cervejarias por Região do RS

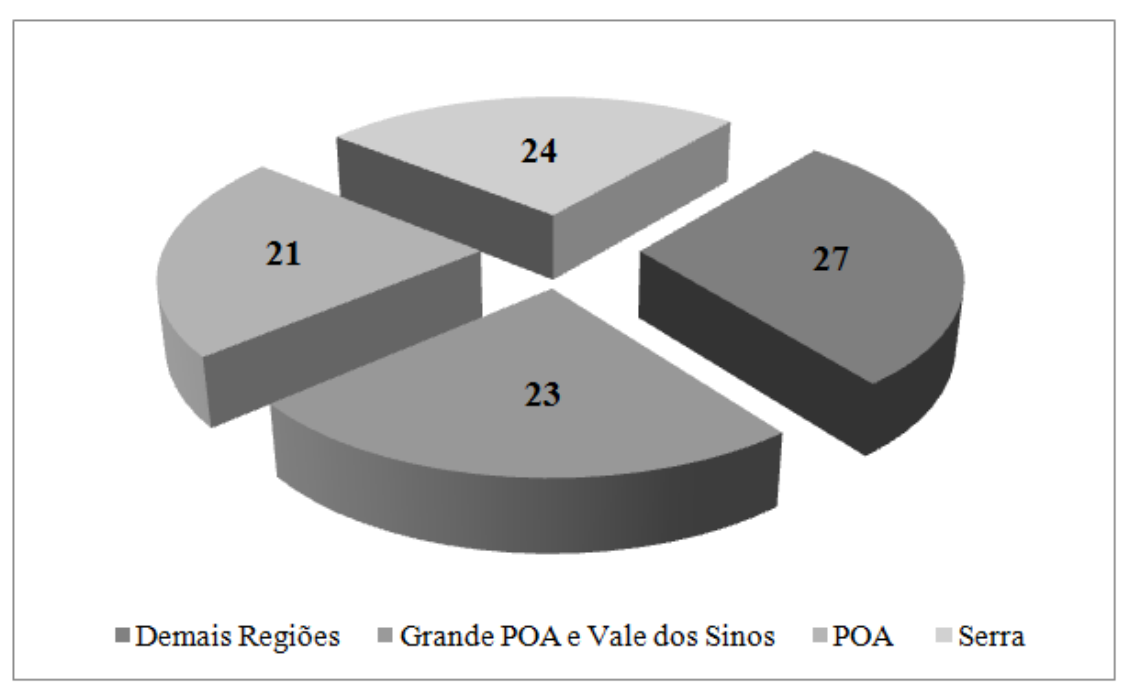

Fonte: Adaptado de MAPA (2016)

A partir da primeira divisão do estado em regiões, foram criadas 3 subcategorias de tamanho, baseadas na produção mensal em litros das cervejarias, sendo: i) produção de 1.000 litros até 15.000 litros; ii) produção de 16.000 litros até 50.000 litros e; iii) produção acima de 50.000 litros. Nesse sentido, a pesquisa exploratória buscou identificar dentro de cada região, no mínimo uma cervejaria de cada uma das 3 categorias de produção em litros acima apresentadas, considerando que, como a pesquisa foi de caráter exploratório, foi possível concluir o levantamento de dados no momento em que os resultados se tornaram repetitivos.

Para levantamento dos dados, foram contatadas ao todo 24 cervejarias (6 de cada região), nas quais 18 concordaram em participar da entrevista, o que representa 18,36\% da população total do estudo (98 cervejarias). A amostra final explorada contemplou 4 cervejarias de Porto Alegre, 6 cervejarias da Grande Porto Alegre e Vale dos Sinos, 5 cervejarias da Serra e 3 cervejarias das demais regiões do estado. Nesse sentido, de acordo com as necessidades de levantamento de dados, considera-se que a amostra realizada foi suficiente para definição das práticas utilizadas atualmente no mercado cervejeiro gaúcho.

A aplicação das pesquisas para levantamento dos dados nas cervejarias selecionadas na amostra foi realizada em entrevistas presenciais realizadas pelo autor através de um roteiro de pesquisa definido como sendo semiestruturado, ou seja, permitindo a abertura para inclusão de informações adicionais não constantes inicialmente. Para garantir a eficácia do levantamento de dados através do roteiro, o mesmo foi validado inicialmente em 3 cervejarias da amostra selecionada. Após a aplicação, foram necessários 
ajustes, sendo estes realizados e o roteiro final aplicado para complementação da amostra.

Os dados da validação também foram incorporados no resultado da pesquisa. Após as alterações, o roteiro definitivo ficou constituído de uma seção inicial, considerando informações gerais de porte e identificação da empresa e de duas perguntas amplas, a saber: "Questão 1 - Atualmente, quais práticas relacionadas à educação ambiental já foram realizadas pela cervejaria para capacitação dos seus colaboradores?" e "Questão 2 - Quais práticas relacionadas à educação ambiental a sua empresa pratica visando a transformação da comunidade em que está inserida?". Todas as pesquisas foram precedidas por uma abordagem inicial com uma breve explicação sobre o conceito de educação ambiental, visando eliminar quaisquer desvios de entendimento dos entrevistados em relação às perguntas realizadas. As respostas dadas por cada cervejaria às perguntas foram anotadas pelo entrevistador para posterior análise.

Após a realização das entrevistas, os dados levantados nas cervejarias foram lançados em planilha eletrônica e analisados, primeiramente, em relação ao perfil das participantes e após os resultados das práticas identificadas foram transcritos e organizados na seção 4 deste trabalho. A Figura 3 apresenta as cervejarias entrevistadas, região e cidade onde estão localizadas, produção média mensal em litros e quantidade de funcionários trabalhando no processo.

Figura 3: Perfil das cervejarias entrevistadas

\begin{tabular}{|c|c|c|c|c|c|}
\hline Referência & Região & Cidade & Categoria & Produção (litros) & Funcionários \\
\hline Cervejaria 01 & POA & Porto Alegre & 16.000 a 50.000 litros & 20.000 & 6 \\
\hline Cervejaria 02 & POA & Porto Alegre & 1.000 a 15.000 litros & 7.000 & 2 \\
\hline Cervejaria 03 & POA & Porto Alegre & Acima de 50.000 litros & 80.000 & 8 \\
\hline Cervejaria 04 & POA & Porto Alegre & 1.000 a 15.000 litros & 4.000 & 2 \\
\hline Cervejaria 05 & Grande POA e VS & Canoas & 1.000 a 15.000 litros & 10.000 & 5 \\
\hline Cervejaria 06 & Grande POA e VS & Eldorado do Sul & 1.000 a 15.000 litros & 7.000 & 2 \\
\hline Cervejaria 07 & Grande POA e VS & Alvorada & 16.000 a 50.000 litros & 25.000 & 10 \\
\hline Cervejaria 08 & Grande POA e VS & Novo Hamburgo & 1.000 a 15.000 litros & 2.000 & 2 \\
\hline Cervejaria 09 & Grande POA e VS & Capela de Santana & 16.000 a 50.000 litros & 30.000 & 7 \\
\hline Cervejaria 10 & Grande POA e VS & Campo Bom & Acima de 50.000 litros & 80.000 & 22 \\
\hline Cervejaria 11 & Serra & Gramado & Acima de 50.000 litros & 80.000 & 6 \\
\hline Cervejaria 12 & Serra & Canela & 1.000 a 15.000 litros & 6.000 & 2 \\
\hline Cervejaria 13 & Serra & Bento Gonçalves & Acima de 50.000 litros & 60.000 & 10 \\
\hline Cervejaria 14 & Serra & Nova Petrópolis & 16.000 a 50.000 litros & 16.000 & 9 \\
\hline Cervejaria 15 & Serra & Nova Petrópolis & 1.000 a 15.000 litros & 6.000 & 2 \\
\hline Cervejaria 16 & Demais Regiões & Passo Fundo & 1.000 a 15.000 litros & 15.000 & 8 \\
\hline Cervejaria 17 & Demais Regiões & Santa Maria & Acima de 50.000 litros & 500.000 & 82 \\
\hline Cervejaria 18 & Demais Regiões & Santa Cruz do Sul & 16.000 a 50.000 litros & 50.000 & 8 \\
\hline
\end{tabular}

Fonte: autor 
Após a realização das pesquisas é importante salientar que o objetivo de entrevistar no mínimo uma cervejaria de cada uma das subcategorias de porte foi atingido em sua totalidade e que a amostra foi suficiente devido à repetição das respostas entre as cervejarias.

\section{Resultados e discussões}

A partir da realização das entrevistas com as cervejarias, esta seção apresenta os resultados das investigações realizadas com base no objetivo de analisar as abordagens de educação ambiental atualmente praticadas pelas cervejarias do Rio Grande do Sul. Em alguns casos, as respostas dadas pelos proprietários que responderam as perguntas foram semelhantes, com respostas diferentes mas que tem o mesmo significado, havendo apenas a utilização de palavras diferentes. Estas respostas foram agrupadas e as práticas identificadas resumidas na Figura 4 juntamente com o número de cervejarias que a utilizam (do total de 18 entrevistas).

Figura 4: Práticas de educação ambiental nas cervejarias do RS

\begin{tabular}{|c|c|c|}
\hline Questão & Prática & Frequência \\
\hline \multirow{4}{*}{$\begin{array}{l}\text { Atualmente, quais práticas relacionadas à } \\
\text { educação ambiental já foram realizadas pela } \\
\text { cervejaria para capacitação dos seus } \\
\text { colaboradores? }\end{array}$} & $\begin{array}{lcr}\text { Treinamento de } \quad \text { integração } & \text { com } \\
\text { abordagens } & \text { relacionadas } & \text { ao } \\
\text { reaproveitamento da água } & \end{array}$ & $\begin{array}{l}22 \% \\
(4 \text { respostas })\end{array}$ \\
\hline & $\begin{array}{l}\text { Abordagens de reciclagem de resíduos de } \\
\text { bagaço de malte }\end{array}$ & $\begin{array}{c}100 \% \\
(18 \text { respostas })\end{array}$ \\
\hline & Reutilização do fermento & $\begin{array}{c}50 \% \\
(9 \text { respostas) }\end{array}$ \\
\hline & $\begin{array}{l}\text { Auxílios visuais de orientação em } \\
\text { relação à reciclagem, consumo de } \\
\text { energia elétrica e água }\end{array}$ & $\begin{array}{l}28 \% \\
(5 \text { respostas })\end{array}$ \\
\hline \multirow{3}{*}{$\begin{array}{l}\text { Quais práticas relacionadas à educação } \\
\text { ambiental a sua empresa pratica visando a } \\
\text { transformação da comunidade em que está } \\
\text { inserida? }\end{array}$} & $\begin{array}{l}\text { Incentivo ao desenvolvimento de novas } \\
\text { alternativas de reciclagem }\end{array}$ & $\begin{array}{c}5 \% \\
(1 \text { respostas })\end{array}$ \\
\hline & $\begin{array}{l}\text { Subsídio para estudo da redução de } \\
\text { consumo de matérias-primas }\end{array}$ & $\begin{array}{l}5 \% \\
(1 \text { resposta })\end{array}$ \\
\hline & $\begin{array}{l}\text { Campanha para devolução das garrafas } \\
\text { de vidro para reutilização }\end{array}$ & $\begin{array}{c}83 \% \\
(15 \text { respostas })\end{array}$ \\
\hline
\end{tabular}

Fonte: Autor

Rev. Eletrônica Mestr. Educ. Ambient. Rio Grande, v. 37, n. 3, p. 9-26, mai./ago. 2020. 
Além da identificação de cada uma das práticas conforme respostas dadas nas entrevistas e como o roteiro aplicado foi um roteiro semi-estruturado, foi possível explorar um pouco mais cada uma das práticas citadas e apresentadas na Figura 4. Nesse sentido, uma descrição mais ampliada de cada prática é apresentada nas subseções que seguem.

\section{Prática 1 - Treinamento de integração com abordagens relacionadas ao reaproveitamento da água}

Esta prática de educação ambiental, citada por 4 cervejarias, está inserida dentro do programa de integração de funcionários destas empresas. A principal relação que é feita, refere-se ao alto consumo de água dentro do processo cervejeiro, tanto no que se refere à produção da cerveja, como na lavagem dos equipamentos utilizados durante esta produção. Através de uma cartilha de integração e um treinamento presencial, as empresas destacam e incentivam seus colaboradores a reutilizarem a água dos resfriadores para a lavagem dos equipamentos e também conscientização para a economia da água durante a sua utilização.

\section{Prática 2 - Abordagens de reciclagem de resíduos de bagaço de malte}

Todas as cervejarias entrevistadas atuam na reciclagem do bagaço de malte para uso como ração animal. Apesar de não haver uma abordagem diretamente educacional nesta prática, é importante salientar que esta possibilidade surgiu e que é disseminada entre as cervejarias. A cada nova cervejaria aberta, as cervejarias mais antigas compartilham práticas através da Associação das Cervejarias, ampliando a consciência de todos em relação aos destinos mais limpos para seus resíduos.

\section{Prática 3 - Reutilização do fermento}

Esta prática tem relação direta com o processo produtivo e é realizada por metade das cervejarias entevistadas. Ao invés do descarte inconsciente das leveduras (fermento) na rede de esgoto após o primeiro uso, as cervejarias desenvolveram pesquisas e instruções de trabalho que auxiliam os funcionários a realizar o processo de reutilização da melhor forma possível. Para este estudo, esta foi considerada uma prática de educação ambiental pois as instruções de reutilização apresentadas destacam em seu conteúdo os benefícios ambientais de se realizar este processo. 
Prática 4 - Auxílios visuais de orientação em relação à reciclagem, consumo de energia elétrica e água

Assim como muitas empresas de outros ramos de atividade, 5 cervejarias entrevistas trabalham com auxílios visuais orientativos quando ao consumos de água nas copas, banheiros e nas áreas de produção. Avisos como "desligue a torneira", "apague a luz ao sair" são utilizados em todas as áreas das empresas com o objetivo de criar nas pessoas uma cultura de preservação dos recursos naturais.

\section{Prática 5 - Incentivo ao desenvolvimento de novas alternativas de reciclagem}

Esta prática, classificada como uma prática de interação com a comunidade local, é realizada por uma cervejaria e tem como objetivo incentivar a população do município onde está inserida a desenvolver novas alternativas para reciclagem dos resíduos de bagaço de malte oriundo do processo de fabricação. A partir da adoção desta prática, um grupo local conseguiu, através da doação do bagaço pela cervejaria, desenvolver um pão onde $30 \%$ da farinha foi trocada pelo bagaço. Esta é, além de uma alternativa importante em relação ao aspecto ambiental, uma abordagem também social, visto que os pães são vendidos e o dinheiro arrecadado revertido para melhorias sociais da comunidade.

A cervejaria que implementou esta prática salienta que muitas outras alternativas podem ser desenvolvidas a partir da reciclagem do bagaço e que continuará com esse envolvimento com a comunidade.

\section{Prática 6 - Subsídio para estudo da redução de consumo de matérias-primas}

Uma das cervejarias entrevistas formou uma parceria com uma Universidade local para o desenvolvimento e estudo de novas fórmulas que mantenham a qualidade do produto mas que auxiliem na redução do consumo de água e de malte no processo produtivo. Com esta prática é possível trazer para a discussão acadêmica o trabalho na redução do consumo de recursos naturais, tendo como base o incentivo de uma cervejaria. Foi salientado pelo gestor entrevistado que, além da abordagem econômica que se tem a partir da redução do consumo de matéria-prima, a cervejaria tem como valor a preservação do meio ambiente, sendo de total interessa dela trabalhos que incentivem e auxiliem na conscientização de todos em relação às questões ambientais. 


\section{Prática 7 - Campanha para devolução das garrafas de vidro para reutilização}

Esta prática foi citada por todas as cervejarias entrevistadas nas quais há a utilização de garrafas de vidro para envasamento (3 cervejarias vendem apenas a cerveja em barril). Nesse sentido, as cervejarias apostam em publicações on-line, folders e mensagens nos rótulos das cervejas, os quais explicam e trazem à tona a discussão e a necessidade de que as garrafas retornem ao produtor para posterior reutilização. Foi salientado por um proprietário de uma cervejaria entrevistado que, para a cervejaria, é mais fácil e econômico comprar novas garrafas devido ao processo de limpeza necessário após o consumo, porém as questões ambientais não podem ser deixadas de lado nesse caso e por isso, trabalha na conscientização das pessoas em relação à devolução dos cascos.

A partir os resultados apresentados e detalhados em relação a estas 7 práticas de educação ambiental, é possível afirmar que, apesar de todos os entrevistados terem dificuldades iniciais de entender o conceito de educação ambiental, a educação ambiental é realizada pelas cervejarias, algumas já avançadas em relação a algumas delas, outras em estágio ainda inicial, mas todas já com alguma prática em andamento e mesmo estas não tendo sido criadas com o objetivo da educação ambiental, trazem consigo um pouco do conceito em sua definição.

\section{Considerações finais}

As abordagens de gestão ambiental tem sido ampliadas constantemente nos últimos anos e, entende-se que para que uma organização consiga gerir de forma adequada seus processos, deve ter um sistema ambiental alicerçado por uma boa base de educação. Nesse sentido, este trabalho buscou explorar o segmento cervejeiro do estado do Rio Grande do sul, objetivando identificar, dentre as 98 empresas atualmente registradas pelo Ministério da Agricultura, práticas de educação ambiental atualmente implementadas por estas empresas, tanto no que se refere aos seus processos internos como também na interação com as comunidades nas quais estão inseridas.

Os resultados alcançados demonstram que, apesar de o conceito de educação ambiental ainda não ser de domínio das empresas, muitas práticas já são realizadas visando envolver e conscientizar as pessoas da organização e da comunidade em relação a uma maior atuação na preservação do meio ambiente. No que se refere a esta questão, entende- 
se que muitas ações são realizadas, porém ainda não é de entendimento coletivo que estas ações impactam diretamente no meio ambiente.

Foram identificadas, entre as cervejarias entrevistadas, 7 práticas já implementadas e que são desenvolvidas muitas vezes sem que se perceba que a educação ambiental está acontecendo. Estas práticas também, detalhadas e citadas como: treinamento de integração com abordagens relacionadas ao reaproveitamento da água; abordagens de reciclagem de resíduos de bagaço de malte; reutilização do fermento; auxílios visuais de orientação em relação à reciclagem, consumo de energia elétrica e água; incentivo ao desenvolvimento de novas alternativas de reciclagem; subsídio para estudo da redução de consumo de matériasprimas e; campanha para devolução das garrafas de vidro para reutilização, podem ser aind ampliadas e implementadas também em outros segmentos industriais, pois em grande parte representam ações genéricas e que podem ser adaptadas às especificidades de cada processo.

A partir deste artigo, sugere-se como estudos futuros a ampliação da aplicação da pesquisa aqui restrita a cervejarias, a outros ramos de negócio, podendo inclusive ser feitas comparações entre práticas em vários segmentos e a realização de estudos de caso para implementação de práticas entre empresas e setores.

\section{Referências}

ACRE, Domitilla Medeiros; CASTILHO, Fábio Roberto. Gestão Ambiental Aplicada ao Setor Gastronômico: Propostas para Dourados-MS. ROSA DOS VENTOS -Turismo e Hospitalidade, v. 5, n. 2, 2013.

ANCIETA MELGAR, Maria José; VAN BELLEN, Hans Michael; LUNKES, Rogério João. Educação Ambiental nas Empresas: um Estudo de Caso na Fischer Fraiburgo Agrícola Ltda. Revista Contemporânea de Contabilidade, v. 3, n. 6, 2006.

ASSIS, Ana Elisa Spaolonzi Queiroz; RUTKOWSKI, Emilia Wanda. Educação Ambiental como estratégia metodológica da Gestão Ambiental: Por uma nova postura epistêmica. Revista Eletrônica Mestrado Educação Ambiental, v. 33, n.3, p. 110124, set./dez., 2016.

BACHA, Maria de Lourdes; SANTOS, Jorgina; SCHAUN, Angela. Considerações teóricas sobre o conceito de sustentabilidade. VII Simpósio de excelência em gestão e tecnologia, 2010.

BARBIERI, José Carlos. Gestão ambiental empresarial: conceitos, modelos e instrumentos/ José Carlos Barbieri- São Paulo: Saraiva. 2004. 
BILITEWSKI, Bernd. The circular economy and its risks. 2012.

BRASIL. Lei 9.795, de 27 de abril de 1999. Dispõe sobre a Educação Ambiental, institui a Política Nacional de Educação Ambiental e dá outras providências. Brasília: Casa Civil, 1999.

BRASIL-MAPA (Ministério do Agricultura, Pecuária e Abastecimento), 2016. Registros de Estabelecimentos. Acesso em 15/04/2016. Disponível em: http://www.agricultura .gov.br/vegetal/registros-autorizacoes/registro/registro_de_estabelecimentos BRAUNGART, M., MCDONOUGH, W., BOLLINGER, A. Cradle-to-cradle design: creating healthy emissions - a strategy for eco-effective product and system design. Journal of Cleaner Production, 1-12, 2006.

DE ANDRADE, José Baltazar Salgueirinho Osório et al. A proposal of a Balanced Scorecard for an environmental education program at universities. Journal of Cleaner Production, 2016.

DONAIRE, Denis. Gestäo ambiental na empresa. Atlas, 1999.

FESZTEROVA, Melania; JOMOVA, Klaudia. Character of Innovations in Environmental Education. Procedia-Social and Behavioral Sciences, v. 197, p. 1697-1702, 2015. GERHARDT, T.E., SILVEIRA, D.T. Métodos de Pesquisa. Porto Alegre, Editora da UFRGS, 2009.

GRAHAN, Stephanie, POTTER, Antony. Environmental operations management and its links with proactivity and performance: A study of the UK food industry. International Journal of Production Economics: 170, 146-159, 2015.

HOFER, Christian; CANTOR, David E.; DAI, Jing. The competitive determinantes of a firm's environmental management activities: evidence form US manufacturing industries. Journal of Operations Management: 30, 69-84, 2012.

JACOBI, Pedro. Educação e meio ambiente - transformando as práticas. Revista Brasileira de Educação Ambiental, 28-35, 2004.

JICKLING, Bob, WALS, Arjen. Globalization and environmental education: looking beyond sustainable development. Journal of Curriculum Studies. 1-21, 2008.

KITZMANN, Dione IS; ASMUS, Milton L. do treinamento à Capacitação: a Inserção da Educação Ambiental no Setor Produtivo. Educação Ambiental: abordagens múltiplas. Porto Alegre: Artmed, 2002.

KUEHR, Ruediger. Towards a sustainable society: United Nations University's Zero Emissions Approach. Journal of Cleaner Production: 15, 1198-1204, 2007.

LUCAS, Marilyn; NOORDEWIER, Thomas. Environmental management practices and firm financial performance: The moderating effect of industry pollution-related factors. International Journal of Production Economics: 175, 24-34, 2016. 
MELGAR, Maria José Ancieta. Educação Ambiental nas Empresas: um Estudo de Caso na Fischer Fraiburgo Agrícola Ltda. Dissertação de Mestrado, UFSC, 2005.

MEZINSKA, Iveta; STRODE, Santa. Emerging horizons of environmental management in food sector companies. In: 20th International Scientific Conference Economics Management - 2015 (ICEM-2015). Procedia - Social and Behavorial Sciences: 213, 527-532, 2015.

MURRAY, Alan; SKENE, Keith; HAYNES, Kathryn. The circular economy: An interdisciplinary exploration of the concept and application in a global context. Journal of Business Ethics, v. 140, n. 3, p. 369-380, 2017.

MUSSATTO, Solange; DRAGONE, Giuliano; ROBERTO, Inês Conceicao. Brewers' spent grain: generation, characteristics and potential applications. Journal of Cereal Science: 43, 1-14, 2006.

OLAJIRE, Abass, The brewing industry and the environmental challenges. Journal of Cleaner Production. doi: 10.1016/j.jclepro.2012.03.003, 2012.

PAIVA, Paulo Roberto de. Contabilidade ambiental. São Paulo: Atlas, 2003.

RAMUS, Catherine. Encouraging innovative environmental actions: what companies and managers must do. Journal of World Business, 37, v.2, 151-164, 2002.

RIVERA, Alejandro et al. Operational change as a profitable cleaner production tool for a brewery. Journal of Cleaner Production, v. 17, n. 2, p. 137-142, 2009.

RODRÍGUEZ, José Manuel Mateo; DA SILVA, Edson Vicente. Educação ambiental e desenvolvimento sustentável: problemática, tendências e desafios. Fortaleza: Edições UFC, 2009.

SANTANA, Antônio. Educação Ambiental e as empresas: um caminho para a sustentabilidade. Educação ambiental em ação, n. 24, 2008.

SILVA, Margane, MARTINS, Danielle Paula. Educação Ambiental empresarial: estudo de caso de uma indústria pet food. In: XVII ENGEMA, 2015.

TINOCO, João Eduardo Prudêncio; PEREIRA, Maria Elisabeth. Contabilidade Ambiental e Gestão Ambiental. 2. ed. São Paulo: Atlas, 2008

THEODORSON, George; THEODORSON, Achilles. A modern dictionary of sociology. London, Methuen, 1970.

UNEP - UNITED NATIONS ENVIRONMENT PROGRAMM. Acesso em 01/09/2017. Disponível em http://www.unep.org/resourceefficiency/Home/WhatisSCP/tabid/105574/ Default.aspx

VAN BERKEL, Rene. Cleaner production and eco-efficiency initiatives in Western Australia 1996-2004. Journal of Cleaner Production, v. 15, n. 8, p. 741-755, 2007. 
VILELA JUNIOR, Alcir; DEMAJOROVIC, Jacques. Modelos e ferramentas de gestão ambiental: desafios e perspectivas para as organizações. In: Modelos e ferramentas de gestão ambiental: desafios e perspectivas para as organizações. SENAC São Paulo, 2006.

WITJES, Sjors; LOZANO, Rodrigo. Towards a more Circular Economy: Proposing a framework linking sustainable public procurement and sustainable business models.

Resources, Conservation and Recycling: 112, 37-44, 2016.

Submetido em: 29-09-2017.

Publicado em: 21-08-2020. 